The trial was generally well done and the procedures reasonably described. However, the researchers did not, from a cognitivebehavioural perspective, treat maternal depression. Cooper et al describe that treatment used cognitive-behavioural techniques but focused not on depression but on the management of mother-infant interactions.

Several randomised placebo-controlled trials have shown that CBT - when done properly-is an effective treatment for post-partum depression (Holden et al, 1989; Appleby et al, 1997; Chabrol et al, 2002) and for major depressive disorders (Hollon et al, 2002). There is an important relationship between post-partum depression and mother-infant interactions but it is not, by any means, the entirety or even the essence of post-partum depression. Although it is advisable to customise CBT to patients' circumstances, exclusive use of one focus, such as mother-child interactions, is not a test of the therapy. If the goal is to change depression, one should treat depression. Thus, the title is inaccurate and the discussion of the lack of effect of CBT for maternal depression is misleading.

Appleby, L., Warner, R., Whitton, A., et al (1997) A controlled study of fluoxetine and cognitive-behavioural counselling in the treatment of postnatal depression. BM), 314, 932-936.

Chabrol, H., Teissedre, F., Saint-Jean, M., et al (2002) Prevention and treatment of post-partum depression: a controlled randomized study on women at risk. Psychological Medicine, 32, 1039-1047.

Cooper, P. J., Murray, L., Wilson, A., et al (2003) Controlled trial of the short- and long-term effect of psychological treatment of post-partum depression. I. Impact on maternal mood. British Journal of Psychiatry, 182, 412-419.

Holden, J. M., Sagovsky, R. \& Cox, J. L. (1989) Counselling in a general practice setting: controlled study of health visitor intervention in treatment of postnatal depression. BMJ, 298, 223-226.

Hollon, S. D., Haman, K. L. \& Brown, L. L. (2002) Cognitive-behavioral treatment of depression. In Handbook of Depression (eds I. H. Gotlib \& C. L. Hammen), pp. 383-403, New York: Guilford Press.

P. J. McGrath Psychology Department Dalhousie University, Halifax, and IWK Health Centre, Halifax B3H 4JI, Nova Scotia, Canada F. J. Elgar School of Social Sciences, Cardiff University, Cardiff, UK

C. Johnston Department of Psychology, University of British Columbia, Vancouver, British Columbia, Canada

D. J. A. Dozois Department of Psychology, University of Western Ontario, London, Ontario, Canada

S. Reyno Dalhousie University, Halifax, Nova Scotia, Canada
Authors' reply: There are many cognitivebehavioural therapies, with the precise form of the CBT shaped to the nature and context of the particular disorder. So, for example, CBT for panic disorder and CBT for bulimia nervosa (Hawton et al, 1989), although sharing a basic orientation and broad therapeutic principles, are very different from one another. The form of CBT in which we were interested had as its principal focus the mother-infant relationship and aspects of infant management. The reason for this was quite clear. It is well established that many forms of treatment for post-partum depression, including counselling (Holden et al, 1989), interpersonal psychotherapy (O'Hara et al, 2000), 'cognitive-behavioural counselling' (Appleby et al, 1997) and fluoxetine (Appleby et al, 1997), have significant antidepressant effects, but it has not been established that any of these interventions has an impact on the quality of the mother-infant relationship and child developmental progress, both known to be compromised in the context of post-partum depression. (The evidence for the efficacy of CBT in this context is, incidentally, less certain. Indeed, none of the three studies cited by Professor McGrath and colleagues in support of this form of treatment delivered an orthodox CBT; and one, in fact, was not a study of CBT at all, but of non-directive counselling.) We were interested in determining whether treatment that addressed the maternal role, as part of a wider supportive therapeutic relationship, would have wider benefits. The form of CBT we investigated was shaped by these concerns, and the discussion refers explicitly to this treatment and is, therefore, wholly apposite.

In several respects the findings of our trial were not what we had expected and were, to us, disappointing. However, the data were what they were, and it was our job to try to understand them. When the first trials comparing CBT with interpersonal psychotherapy for major depression were published in the 1980s, British clinical psychology reverberated with the chunterings of the CBT faithful whose instinctive reaction to the equivalence conclusion was to query the probity of the trial CBT therapists. With time, a more mature position was evolved. The findings of our study, along with the broad failure of the trials of preventive treatments for post-partum depression, would seem to us to be cause for pause and reflection, rather than instinctive defensiveness.
Appleby, L., Warner, R., Whitton, A., et al (1997) A controlled study of fluoxetine and cognitive-behavioural counselling in the treatment of postnatal depression. BM), 314, 932-936.

Hawton, K., Salkovskis, P., Kirk, J., et al (1989) Cognitive Behaviour Therapy for Psychiatric Problems: A Practical Guide. Oxford: Oxford University Press.

Holden, J. M., Sagovsky, R. \& Cox, J. L. (1989)

Counselling in a general practice setting: controlled study of health visitor intervention in treatment of postnatal depression. BMJ, 298, 223-226.

O'Hara, M., Stuart, S. \& Gormon, L. L., et of (2000) Efficacy of interpersonal psychotherapy for postpartum depression. Archives of General Psychiatry, 57. 1039-1045.

P. J. Cooper, L. Murray Winnicott Research Unit, Department of Psychology, University of Reading, Whiteknights, 3 Earley Gate, Reading, Berkshire RG6 6AL, UK

\section{Cognitive-behavioural therapy as a treatment for psychosis}

McKenna (2003) comments that Sensky et al (2000), in their trial of cognitivebehavioural therapy (CBT) $v$. befriending for the treatment of schizophrenia, found no advantage of CBT over befriending at the end of the 9-month intervention period. In his view, they were therefore not justified in making the claim that CBT is effective in treating negative as well as positive symptoms in schizophrenia. This assertion fails to recognise the different mechanisms by which CBT and drugs may benefit psychotic symptoms. While drugs are likely to produce a (relatively) immediate effect in altering neurotransmitter pathways, CBT (as is the case with other psychological therapies) is postulated to alter attachmentrelated memory (Gabbard, 2000) and develop an understanding of the illness. Cognitive-behavioural therapy utilises skills which, if successful, can be maintained by the patient long after therapy has ended. This would explain why Sensky et al (2000) witnessed a non-significant difference between the control and intervention groups at the end of the intervention period but a significant continued improvement in those receiving CBT (and not in those receiving befriending) at 9month follow-up. It would not be expected that drugs would maintain a benefit 9 months after being stopped. Preliminary results of a 5-year follow-up of the cohort of patients in this study indicate that these gains in the CBT group have been maintained (D. Turkington, personal communication, 2001). 